\title{
LET'S DO IT!
}

The Southern African HIV Clinicians Society and the Foundation for Professional Development, the educational division of the South African Medical Association, have joined forces to train in the region of 3000 health care practitioners in HIV/AIDS management over the next 3 years.

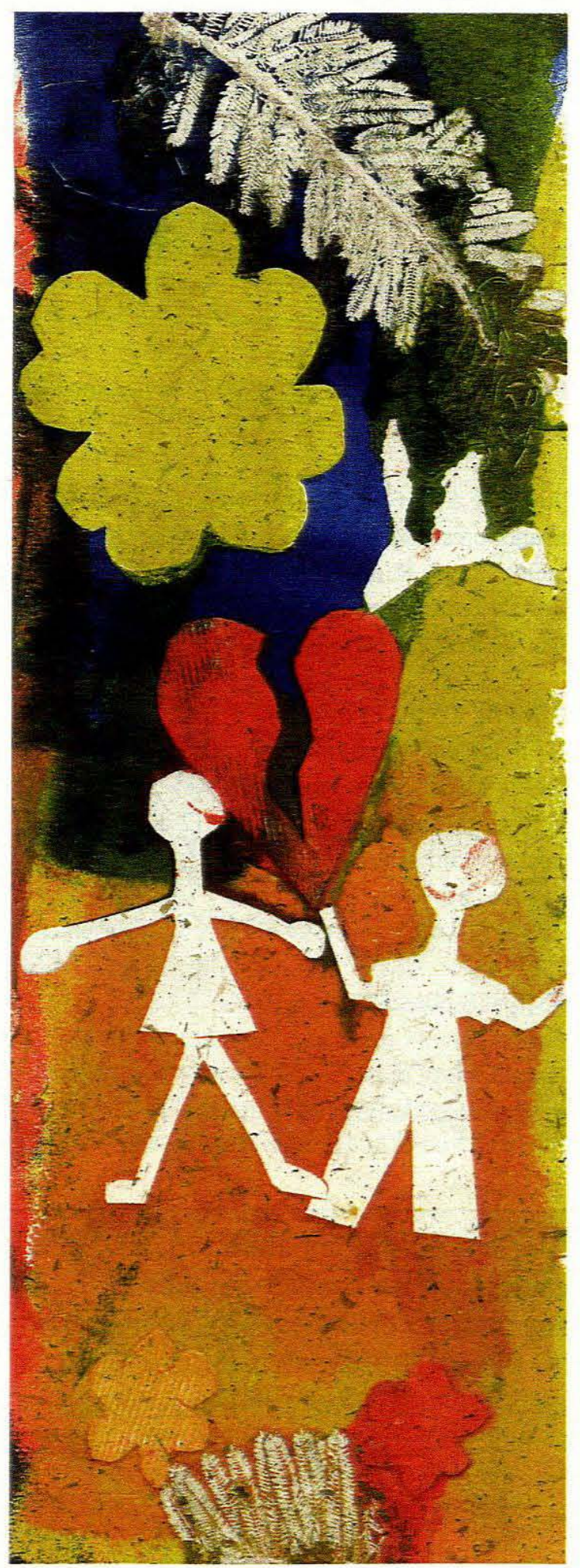

Daily we are confronted by newspaper headlines documenting the enormity of the HIV/AIDS pandemic:

- 10\% of South Africans are HIV-positive

- 5 million South Africans are HIV-positive

- 100000 civil servants are HIV-positive

- 1600 people are infected per day

250000 HIV/AIDS deaths occur every year.

Despite these daily reminders HIV/AIDS remains a condition with which the majority of medical practitioners are unfamiliar. In this country the management of this condition depends on a very small number of experts, far too few to respond adequately to the number of patients requiring treatment and care.

Given the number of HIV-positive South Africans and the growing feasibility of affordable antiretroviral therapy, it is reasonable to view HIV/AIDS as a chronic manageable disease.

While not neglecting the imperative of prevention of HIV/AIDS, it has also become a critical challenge for every health care professional to acquire the skills to manage HIV/AIDS and other sexually transmitted diseases (STDs) and all opportunistic infections associated with HIV. By joining forces the Foundation and the HIV Clinicians Society will actively begin to address this challenge.

The training programme in HIV/AIDS management being launched to coincide with this article will attempt to:

- ensure a critical mass of trained health care professionals within a relatively short period of time

- provide health care professionals with comprehensive skills in order to enable them to diagnose and manage HIV/AIDS and STDs and all related clinical conditions, including referral to specialist and support services

a provide targeted sectors of the health care profession with appropriate and meaningful information to prevent themselves from becoming infected

- establish a support structure that will keep alumni of the programme updated with new developments in the field, and 
- create an expanded organised community of health care professionals dedicated to responding to the HIV/AIDS epidemic.

This training programme will utilise a combination of self-study and 3 days of face-to-face tuition to develop participants' skills in areas such as:

diagnosis of HIV/AIDS and STDs

- basic and clinical management and referral

- counselling

advocacy

a 'living with HIV'.

The self-study material has been developed in collaboration with the International AIDS Society (IAS) to reflect global best practice customised to South African realities.

International sponsorship has also been secured to ensure that cost does not become an obstacle to participation in this training programme.

\section{WHAT IS THE FOUNDATION FOR PROFESSIONAL DEVELOPMENT (FPD)?}

- The FPD is the educational division of the South African Medical Association (SAMA).

- The FPD focuses on helping all health care professionals optimise their skills in order to prosper in a rapidly changing environment.

- Student enrolment. Since the launch of our first course in 1998, student enrolment has grown dramatically (Fig. 1).

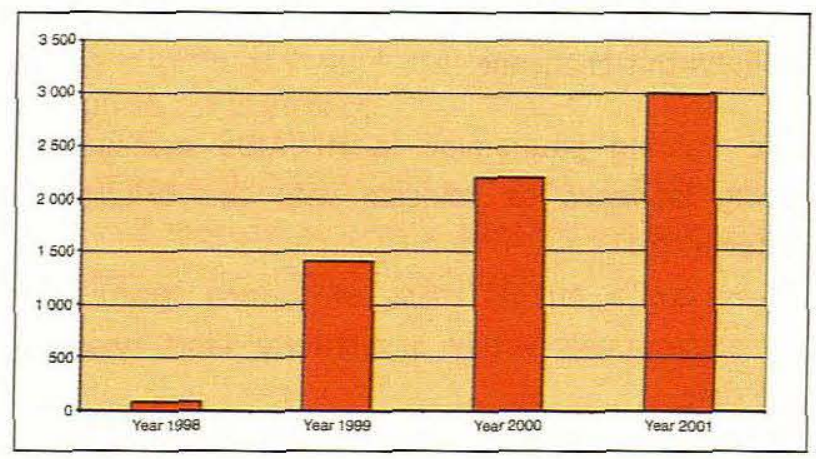

Fig. 1. Student enrolment in the FPD.

\section{WHAT MAKES FPD COURSES SPECIAL?}

Courses are tailor-made to meet the specific needs of health care professionals.

- Comprehensive study guides eliminate the need for expensive textbooks.

- It is acknowledged that time is the most valuable commodity for the health care professional.

- Courses are developed and taught by acknowledged local and international experts in their field from both the private and the public sector.

- Participants evaluate every aspect of our courses from faculty to venue, and we act on these evaluations.

- An active alumni programme exists which keeps participants informed via e-mail or update seminars of new developments in their area of interest.

FPD TRAINING PROGRAMMES FOCUS ON THE FOLLOWING AREAS

Management and leadership development

Practice staff development

Clinical skills development

Corporate training

\section{MANAGEMENT COURSES}

Manchester Business School Advanced Management Programme (part-time 1 year)

Financial Health Course ( 3 days)

Tax Planning Seminar (1 day)

Practice Management Programme (9 months parttime)

\section{PRACTICE STAFF DEVELOPMENT}

Essence of caring course $(2 \times 1 / 2$ days)

Coding Course ( 2 days)

Medical Terminology and Anatomy Course ( 2 days)

Debt Collecting Course ( 2 days)

\section{CLINICAL COURSES}

Rheumatology Management Course (3 days)

Obesity Management Course ( 2 days)

Professional Drivers Permit Course ( 2 days)

Mental Health Course ( 3 days)

Practice Pathology (2 days)

AIDS \& STD Programme (in process of development)

DISTANCE EDUCATION

Medical Ethics Course

Dental Ethics Course

Rheumatology Management Course

For detailed information on any of the courses, please contact the FPD at: Foundation for Professional Development

PO Box 74789, Lynnwood Ridge 0040

Web-site: http://www.foundation.co.za

E-mail: foundation@samedical.org

Tel: (012) 481-2032/3/4

Fax: (012) 481-2083 